\title{
PRODUTIVIDADE E CUSTOS DO CORTE DE PINUS COM HARVESTER DE
} PNEUS E ESTEIRAS

Carlos Henrique Drinko"; Eduardo da Silva Lopes²; Felipe Martins de Oliveira ${ }^{3}$

${ }^{1}$ Graduando em Engenharia Florestal (cdrinko@hotmail.com);

${ }^{2}$ Professor Doutor do Departamento de Engenharia Florestal ${ }^{3}$ Doutorando em Ciências Florestais Universidade Estadual do Centro-Oeste - UNICENTRO, Irati, PR, Brasil.

Recebido em: 08/09/2015 - Aprovado em: 14/11/2015 - Publicado em: 01/12/2015 DOI: http://dx.doi.org/10.18677/Enciclopedia_Biosfera_2015_254

\begin{abstract}
RESUMO
Esse trabalho objetivou realizar uma análise técnica e de custos dos tratores florestais harvester equipados com rodados de pneus e de esteiras no corte de Pinus taeda em regime de corte raso aos 15 anos de idade, produzindo toras com diferentes sortimentos. A análise técnica englobou um estudo de tempos com movimentos, onde a operação de corte foi subdividida em fases do ciclo de trabalho, determinando-se a produtividade, disponibilidade mecânica e eficiência operacional, enquanto a análise de custos contemplou os custos operacionais e de produção. Os resultados mostraram que a fase que consumiu maior tempo do ciclo operacional foi o processamento, com $49 \%$ e $43 \%$ do tempo total para os harvesters de pneus e de esteiras, respectivamente. O tempo de trabalho do harvester de esteiras foi afetado pelo deslocamento no talhão devido a sua menor velocidade comparado à máquina de pneus. O harvester de esteiras apresentou menor produtividade e eficiência operacional, mesmo trabalhando com sortimentos de madeira que favorecia 0 melhor desempenho. A produtividade média e eficiência operacional do harvester de pneus foi de $36,9 \mathrm{~m}^{3} / \mathrm{h}$ e $66,7 \%$, enquanto o harvester de esteiras foi de $35,0 \mathrm{~m}^{3} / \mathrm{h}$ e 63,6\%, respectivamente.
\end{abstract}

PALAVRAS-CHAVE: análise técnica, Colheita florestal, eficiência operacional.

\section{PRODUCTIVITY AND COST OF PINE CUT WITH HARVESTERS OF TIRES AND TRACK WHEEL}

\begin{abstract}
This study aimed to carry out a technical and costs analysis of harvesters equipped with wheel tires and tracks working in a clearcut tree-cutting 15-year-old Pinus taeda, producing wood with different assortments. The technical analysis included a time and motion study, where the cutting operation was divided into phases of the production process, determining productivity, mechanical disponibility and operational efficiency, while the cost analysis included operating and production costs. The results showed that the phase that consumed the most part of operational cycle was processing, with $49 \%$ and $43 \%$ of the total time for harvesters with tires and mats, respectively. The operational time of harvester with tracks wheel was affected by the driving in the stand, explained by the lower speed developed compared to the machine with tires wheel. The harvester with tracks wheel showed ENCICLOPÉDIA BIOSFERA, Centro Científico Conhecer - Goiânia, v.11 n.22; p.3664 2015
\end{abstract}


lower productivity and operational efficiency, even when working with types of assortments that favored the best performance. The average productivity and operational efficiency of the harvester with tires wheel was $36.9 \mathrm{~m}^{3} / \mathrm{h}$ and $66.7 \%$, while the harvester with tracks wheel was $35.0 \mathrm{~m}^{3} / \mathrm{h}$ and $63.6 \%$, respectively.

KEYWORDS: Timber harvesting, rotated, technical analysis, operational efficiency.

\section{INTRODUÇÃO}

$\mathrm{Na}$ cadeia produtiva de florestas plantadas, a colheita e o transporte da madeira são as etapas mais onerosas em termos econômicos, representando mais de $50 \%$ dos custos da madeira colocada na indústria (MACHADO, 2008; OLIVEIRA, 2014). Além disso, é influenciada por diversos fatores técnicos, ambientais, ergonômicos e sociais que interferem diretamente na forma de execução das operações (LOPES, 2001).

O corte é a primeira etapa da colheita de madeira, abrangendo as fases de derrubada, desgalhamento, traçamento, destopamento e empilhamento (SANT'ANNA, 2014), podendo ser conceituado como a derrubada das árvores e sua conversão em sortimentos, incluindo as operações de desgalhamento e empilhamento (PULKKI, 2006). No Brasil, o maior volume de madeira cortada é realizado por métodos mecanizados, com o uso de máquinas como harvesters e feller bunchers, equipados com rodados de pneus e esteiras.

Entretanto, devido aos elevados custos da colheita de madeira, principalmente na etapa do corte, uma alternativa muito adotada pelas empresas florestais tem sido o uso de máquinas de esteiras adaptadas da construção civil equipadas com cabeçote processador, ao invés do uso de máquinas exclusivamente florestais.

Neste sentido, as empresas florestais têm utilizado dois modelos de harvester, podendo ser equipada com rodados de pneus ou esteiras. Os rodados de pneus são comuns nas máquinas de uso exclusivo florestal, enquanto os rodados de esteiras são comuns nas máquinas adaptadas da construção civil ou alguns modelos específicos com configuração florestal.

É importante ressaltar que a opção pelo uso das máquinas de esteiras adaptadas é baseada principalmente no seu menor custo de aquisição, diversidade de modelos existentes no país, facilidade de assistência técnica e de manutenção, bem como devido ao seu maior valor de revenda. Porém, existem argumentos contrários referentes ao uso das máquinas com rodados de esteiras, como o elevado custo de manutenção das esteiras e restrição na operação em terrenos acidentados e com obstáculos (SEIXAS \& BATISTA, 2014). Por fim, deve-se destacar que ambos os modelos de máquinas apresentam vantagens $\mathrm{e}$ desvantagens, tornando-se importante o desenvolvimento de trabalhos que possam contribuir com os gestores na tomada de decisões de qual o modelo mais viável do ponto de vista técnico, econômico e ambiental.

Diante disso, objetivou-se neste trabalho realizar uma análise técnica e de custos de dois tratores florestais harvester equipados com rodados de pneus e esteiras no corte de Pinus taeda com diferentes sortimentos, subsidiando o planejamento das operações para aumento da produtividade e redução dos custos de produção. 


\section{MATERIAL E MÉTODOS}

O trabalho foi realizado nas áreas operacionais de colheita da madeira de uma empresa florestal localizada no Estado do Paraná, entre as coordenadas geográficas $25^{\circ} 58^{\prime} 40^{\prime \prime} \mathrm{S}$ e $49^{\circ} 40^{\prime} 58^{\prime \prime} \mathrm{W}$ e com altitude média de $802 \mathrm{~m}$. A temperatura média da região variou entre $17^{\circ} \mathrm{C}$ a $22^{\circ} \mathrm{C}$, com precipitação média anual de $1400 \mathrm{~mm}$, enquanto o solo predominante foi classificado como argilososiltoso e relevo suave-ondulado.

O estudo foi desenvolvido em plantios de Pinus taeda L., com árvores de volume médio individual com casca de $0,41 \mathrm{~m}^{3}$ e espaçamento $2,5 \mathrm{~m} \times 2,5 \mathrm{~m}$. O regime de manejo utilizado pela empresa era de corte raso executado aos 15 anos de idade, sendo a madeira destinada para diversos clientes.

O sistema de colheita da madeira adotado pela empresa era o de Toras Curtas (cut to lenght). O corte, caracterizado pela derrubada, desgalhamento, traçamento, destopamento e empilhamento das árvores era realizado com uso do harvester. A extração das toras do interior do povoamento até a margem da estrada era realizado pelo forwarder, sendo por fim, realizado o carregamento e transporte final da madeira. Os sortimentos de madeira produzidos são descritos na Tabela 1.

TABELA 1 Sortimentos de madeira produzidos pelas máquinas durante o estudo

\begin{tabular}{cccc}
\hline $\begin{array}{c}\text { Tipo de } \\
\text { rodados do } \\
\text { Harvester }\end{array}$ & Sortimento & $\begin{array}{c}\text { Comprimento } \\
(\mathbf{m})\end{array}$ & $\begin{array}{c}\text { Diâmetro } \\
(\mathbf{c m})\end{array}$ \\
\hline \multirow{3}{*}{ Pneu } & 1 & 2,5 & $\leq 18$ \\
& 2 & 1,9 & 18 a 23 \\
& 3 & 2,65 & 23 a 32 \\
Esteira & 4 & 3,0 & $>32$ \\
& 1 & 2,5 & $\leq 18$ \\
& 2 & 1,9 & 18 a 23 \\
& 3 & 4,1 & 23 a 32 \\
\hline
\end{tabular}

Foram estudados dois modelos de harvesters equipados com rodados de pneus e esteiras (Figura 1). O harvester de pneus era da marca Valmet e modelo 911.3, estando equipado com cabeçote Valmet 360 , enquanto o harvester com rodados de esteiras era da marca Komatsu e modelo PC 200, equipado com cabeçote Valmet 370. Ambas as máquinas foram operadas por operadores experientes e capacitados para a função, considerando que o tempo de experiência afeta significativamente o rendimento operacional (LEONELLO et al., 2012).
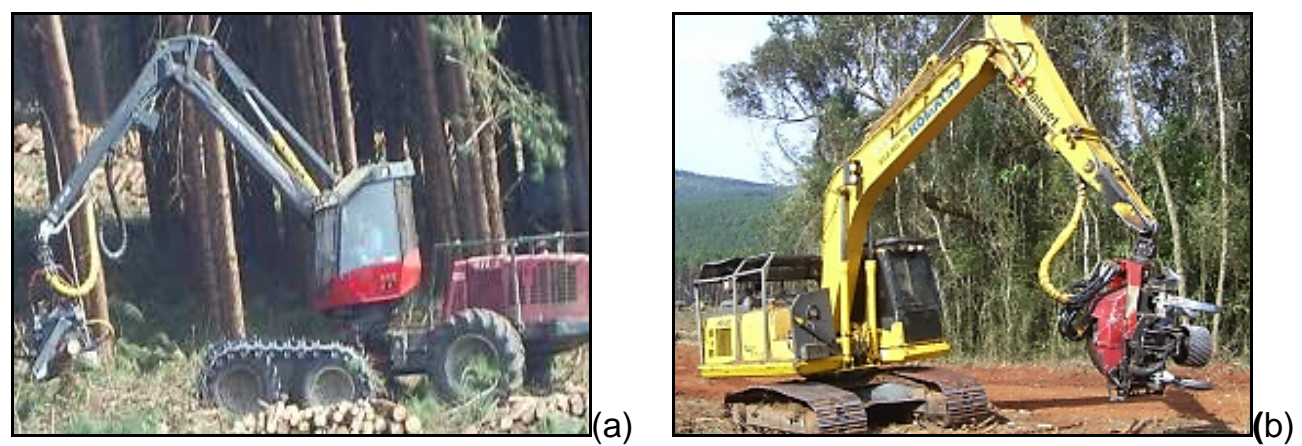

FIGURA 1 Harvester com rodados de pneus (a) e esteiras (b) 
Inicialmente foi realizado um estudo de tempos e movimentos piloto com ambos os modelos de harvesters, de forma a definir o número mínimo de observações necessárias, ao nível de $95 \%$ de probabilidade e erro relativo de $5 \%$, por meio do uso da Equação 1 proposta por BARNES (1977).

$n \geq \frac{t^{2} \times C V^{2}}{E^{2}}$

Em que:

$n$ = número mínimo de ciclos necessários;

$t=$ valor de $t$, para o nível de probabilidade desejado e $(n-1)$ graus de liberdade;

$C V=$ coeficiente de variação, em porcentagem; e

$E=$ erro admissível, em porcentagem.

\section{Análise Técnica}

A análise técnica foi realizada por meio de um estudo de tempos e movimentos do corte florestal em ambas as máquinas, pelo método de cronometragem de tempos contínuos, onde a leitura do cronômetro foi realizada no ponto referente à atividade parcial recém-concluída.

O ciclo operacional de corte foi subdividido nos seguintes elementos parciais: Busca e Corte (BC): tempo consumido pela máquina na derrubada e tombamento da árvore; Processamento (PR): tempo consumido pela máquina no processamento da madeira (desgalhamento, traçamento, destopamento e empilhamento); Deslocamento (DE): tempo consumido pela máquina no deslocamento entre árvores durante a execução do corte; e Interrupções (INT): referente aos tempos em que a máquina não estava realizando as atividades acima mencionadas.

Para a determinação da produtividade de ambas as máquinas foi obtido o volume médio individual das árvores fornecido pelo inventário florestal da empresa, cujo valor foi multiplicado pelo número de árvores cortadas em cada ciclo operacional e, por fim, dividas pelas horas efetivamente trabalhadas por meio da Equação 2.

$P R=\frac{\text { na } \times v a}{h e}$

Em que:

$P R=$ Produtividade $\left(\mathrm{m}^{3} \mathrm{cc} / \mathrm{he}\right)$;

$n a=$ número de árvores cortadas em cada ciclo operacional;

$v a=$ volume médio individual das árvores $\left(\mathrm{m}^{3} \mathrm{cc}\right) ; \mathrm{e}$

$h e=$ tempo efetivo de trabalho (horas).

A disponibilidade mecânica refere-se à porcentagem do tempo de trabalho programado em que a máquina estava mecanicamente apta a realizar o trabalho produtivo, desconsiderando o tempo em manutenção, sendo obtida pela Equação 3.

$D M=\frac{T E}{(T E+T M)} \times 100$ 
Em que:

$D M=$ Disponibilidade Mecânica (\%);

$T E=$ tempo de trabalho efetivo (horas); e

$T M=$ tempo de manutenção (horas).

A eficiência operacional é a porcentagem do tempo efetivamente trabalhado em relação ao tempo total programado para o trabalho, determinada pela Equação 4.

$E O=\frac{T E}{(T E+T I)} \times 100$

Em que:

$E O=$ eficiência operacional (\%);

$T E$ = tempo de trabalho efetivo (hora); e

$T I=$ tempo de interrupções (hora).

A análise dos tempos improdutivos foi realizada de forma qualitativa, identificando e interpretando as diferentes interrupções ocorridas durante o trabalho, analisando as principais causas e consequências.

\section{Análise de Custos}

A análise de custos das máquinas estudadas foi realizada com base no custo operacional e de produção, com uso de metodologias específicas desenvolvidas para máquinas florestais. O custo operacional foi obtido pelo método contábil conforme metodologia proposta por MIYATA (1980) e LOPES (2001), englobando os custos fixos (depreciação, juros e seguros), os custos variáveis (combustíveis, lubrificantes e graxas, óleo hidráulico, pneus, manutenção e reparos e transporte de pessoal) e os custos de pessoal (salário e encargos sociais). O custo de produção foi obtido pela divisão dos custos operacionais $(R \$ / h e)$ pela produtividade $\left(\mathrm{m}^{3} / \mathrm{he}\right)$ da máquina.

\section{Custos fixos}

São aqueles que não variam com as horas trabalhadas, ou seja, ocorrem caso a máquina esteja ou não em operação, sendo compostos pelos custos de depreciação, juros e seguros. Para o cálculo da depreciação foi utilizado o método de depreciação linear, conforme as Equações 5 e 6:

$D P=\frac{V a-V r}{(N+T e)}$

Em que:

$D P=$ depreciação linear da máquina $(\mathrm{R} \$ / \mathrm{he})$;

$V a=$ valor de aquisição da máquina somado ao valor de aquisição do implemento $(R \$)$;

$V r=$ valor residual ou de revenda da máquina mais implemento $(R \$)$;

$N=$ vida útil estimada (anos); e

$T e=$ horas efetivas de uso anual. 
$H e=\frac{N d \times d \times N t \times(100-T D)}{100}$

Em que:

$\mathrm{He}=$ horas efetivas de trabalho por ano (horas);

$N d=$ número de dias trabalhados por ano;

$d=$ duração do turno de trabalho (horas);

$N t=$ número de turnos de trabalho por dia; e

$T D=$ Demoras e dias improdutivos (\%).

Os juros e seguros foram calculados aplicando-se ao investimento médio anual (IMA) uma taxa de juros e seguros, cujas taxas foi de $8 \%$ a.a e de $2 \%$ a.a, respectivamente, totalizando $10 \%$ a.a. O cálculo dos juros e seguros foi realizado por meio das Equações 7 e 8:

$J S=\frac{|M A \times|}{H e}$

Em que:

$J S=$ custos de juros e seguros $(\mathrm{R} \$ / \mathrm{he})$;

$I M A$ = investimento médio anual $(\mathrm{R} \$)$;

$i=$ taxa de juros e seguros (\%); e

$H e=$ horas efetivas de trabalho anual (horas).

IMA $=\frac{(V a-V r) \times(N+1)}{(2 \times N)} \times V r$

Em que:

$V a=$ valor de aquisição da máquina e implemento $(R \$)$;

$V r=$ valor residual ou de revenda da máquina e implemento $(R \$)$; e

$N=$ vida útil estimada da máquina e implemento (anos).

\section{Custos Variáveis}

São custos diretamente ligados com a intensidade de uso da máquina, ocorrendo de acordo com a quantidade produzida ou uso da máquina. Contemplam os custos com combustível, lubrificantes e graxas, óleo hidráulico, pneus e esteiras, manutenção, transporte de máquinas e transporte de pessoal.

O custo de combustível referiu-se ao consumo de óleo diesel, obtido diretamente no diário de bordo da máquina durante a realização do estudo, multiplicado pelo preço de mercado do combustível, obtido pela Equação 9:

$\mathrm{CC}=P u \times C$

Em que:

$C C=$ custo de combustível $(\mathrm{R} \$ / \mathrm{he})$;

$P u=$ preço de um litro de óleo diesel $(\mathrm{R} \$ / \mathrm{L}) ; \mathrm{e}$

$C=$ consumo de óleo diesel por hora efetiva $(\mathrm{L} / \mathrm{he})$. 
O custo de lubrificantes e graxas referiu-se ao consumo de óleos lubrificantes e graxas, correspondente ao percentual de $10 \%$ dos custos com combustíveis utilizados pela empresa e obtido pela Equação 10:

$$
C L G=I L G \times C C
$$

Em que:

$C L G=$ custo com lubrificantes e graxas $(\mathrm{R} \$ / \mathrm{he})$;

ILG = índice de lubrificantes e graxas (10\%); e

$C C=$ custos com combustíveis $(\mathrm{R} \$ / \mathrm{he})$.

O custo de óleo hidráulico referiu-se ao consumo do óleo hidráulico da máquina, obtida na empresa e multiplicado pelo seu custo, e posteriormente computado no cálculo de consumo de lubrificantes e graxas.

O custo de pneus e esteiras referiu-se ao número de pneus ou esteiras multiplicado pelo valor de aquisição e dividido pelas horas trabalhadas, sendo obtido pela expressão 11:

$$
C P=\frac{N r \times V !}{H r}
$$

Em que:

$C P=$ custo dos rodados $(\mathrm{R} \$ / \mathrm{he})$;

$V r=$ valor de um pneu ou esteira da máquina $(\mathrm{R} \$)$;

$\mathrm{Nr}=$ número de rodados (pneus ou esteira) da máquina; e

$H r=$ vida útil de um pneu ou esteira, em horas efetivas (he).

O custo de manutenção e reparos, que se referiu aos custos relacionados com a manutenção preventiva e corretiva das máquinas, foi obtido a partir de dados históricos da empresa.

O custo de pessoal operacional que é composto pelos custos relacionados com salários diretos mais os custos de benefícios e encargos sociais (fundo de garantia, 13o salário, férias, seguros, alimentação, plano de saúde, vestuário e transporte de pessoal), foram obtidos diretamente na empresa, em valores mensais e sendo divididos pelas respectivas quantidades de horas trabalhadas.

O custo de administração composto pelos custos relacionados com os trabalhos de escritório e supervisão de campo foi obtido diretamente na empresa, em valores mensais e divididos pela quantidade de horas trabalhadas. Foi utilizado no cálculo o percentual de $5 \%$ dos custos fixos, variáveis e de pessoal operacional.

\section{Custo Operacional Total}

Este custo foi obtido pelo somatório dos custos fixos, variáveis, pessoal e de administração de ambos os modelos de harvester, por meio da Equação 12:

$C O T=C F+C V+C P+C A D$

Em que:

$C O T=$ custo operacional total $(\mathrm{R} \$ / \mathrm{he})$;

$C F=$ custos fixos ( $R \$ / h e)$; 
$C V=$ custos variáveis $(\mathrm{R} \$ / \mathrm{he})$;

$C P=$ custo de pessoal operacional $(\mathrm{R} \$ / \mathrm{he})$; e

$C A D=$ custo de administração $(\mathrm{R} \$ / \mathrm{he})$.

\section{Custo de Produção}

O custo de produção das máquinas foi obtido pela divisão dos custos operacionais pela produtividade, por meio da Equação 13:

$C P R=\frac{C O T}{P R}$

Em que:

$C P R=$ custo de produção de máquina $\left(\mathrm{R} \$ / \mathrm{m}^{3}\right)$;

$C O T$ = custo operacional total da máquina $(R \$ / h e)$; e

$P R=$ produtividade da máquina $\left(\mathrm{m}^{3} / \mathrm{he}\right)$.

\section{RESULTADOS E DISCUSSÃO}

Neste estudo foram coletados 3.248 e 2.577 ciclos operacionais para os harvesters com rodados de pneus e de esteiras, atendendo à exigência mínima de 1.602 e 1.642 ciclos operacionais definidos pelo estudo piloto, respectivamente. Durante o estudo foram colhidas um total de 5.825 árvores, com um volume médio individual de $0,40 \mathrm{~m}^{3}$ no corte com harvester de pneus e de $0,42 \mathrm{~m}^{3}$ no harvester de esteiras.

Na Figura 2 é apresentada a distribuição percentual dos tempos do ciclo operacional de ambos os modelos harvesters.

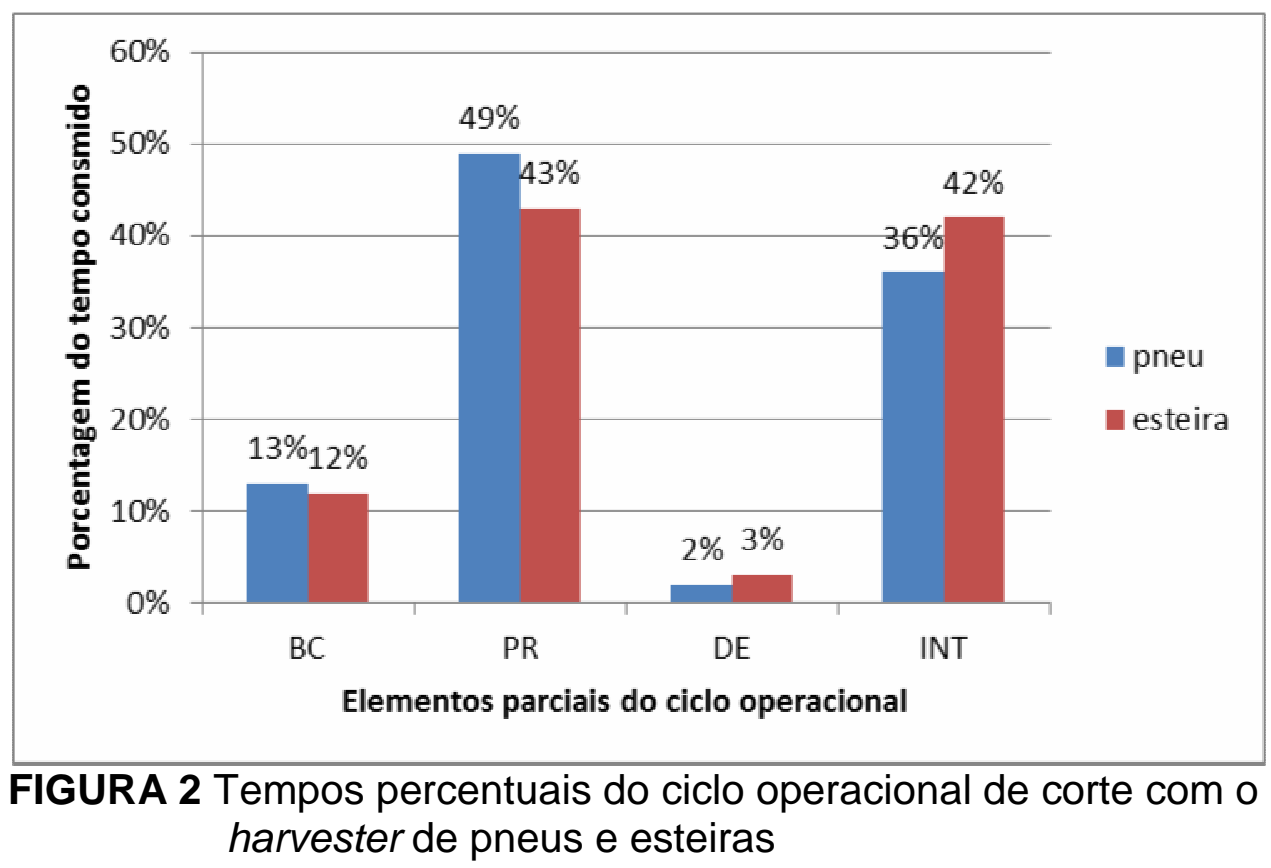

Como pode ser observado, o elemento "processamento" consumiu o maior tempo médio do ciclo operacional, com $49 \%$ do tempo total no harvester de pneus e $43 \%$ no harvester de esteiras. O elevado tempo deveu-se, principalmente, pela quantidade de sortimentos produzidos, situação que acarretou na necessidade de separação e organização das pilhas de madeira nos diferentes sortimentos, 
permitindo um eficiente baldeio da madeira. Entretanto, este tempo foi inferior ao encontrado por SILVA et al. (2010), que observaram um tempo percentual de $66 \%$ do ciclo operacional consumido.

Em seguida, destacou-se os tempos de "interrupções", com $36 \%$ e $42 \%$, respectivamente, nas máquinas de pneus e esteiras, seguido pela "busca e corte", com $13 \%$ em ambas as máquinas, e por fim, pelo "deslocamento", com $2 \%$ e $3 \%$, respectivamente. Por se tratar da mesma operação, porém com máquinas de rodados distintos e com um dos sortimentos diferindo, observa-se a mesma tendência nos tempos demandados, principalmente na fase de busca e corte e de deslocamento da máquina.

É importante ainda ressaltar que, os tempos médios absolutos consumidos por ciclo operacional do harvester de pneus foi de 8 segundos no elemento "busca e corte", 31 segundos no "processamento", 1 segundo no "deslocamento" e 23 segundos para "interrupções". No harvester de esteiras, os tempos médios por ciclo foram 9 segundos na "busca e corte", 33 no "processamento", 2 segundos no "deslocamento" e 32 segundos nas "interrupções".

$\mathrm{Na}$ Figura 3 é mostrada a distribuição percentual média das interrupções operacionais dos harvesters, que consumiu $36 \%$ do tempo total do ciclo operacional na máquina de pneus e $42 \%$ na de esteiras. Cabe destacar que a maior parte das interrupções foi do tipo "operacionais" (IO) em ambas as máquinas, consumindo $36 \%$ e $41 \%$ nas máquinas de pneus e de esteiras, respectivamente. A maior parte do tempo improdutivo foi causada por ações diretamente ligadas à operação em si, mas que não tinham relação com problemas mecânicos. Em seguida, para o harvester de pneus, destacam-se as "interrupções pessoais" (IP) com $34 \%$ e as "interrupções mecânicas" (IM) com 30\% do total de interrupções. Para o harvester de esteiras, inversamente, destacam-se as "interrupções mecânicas" e "interrupções pessoais", com $31 \%$ e $28 \%$ do tempo total, respectivamente.

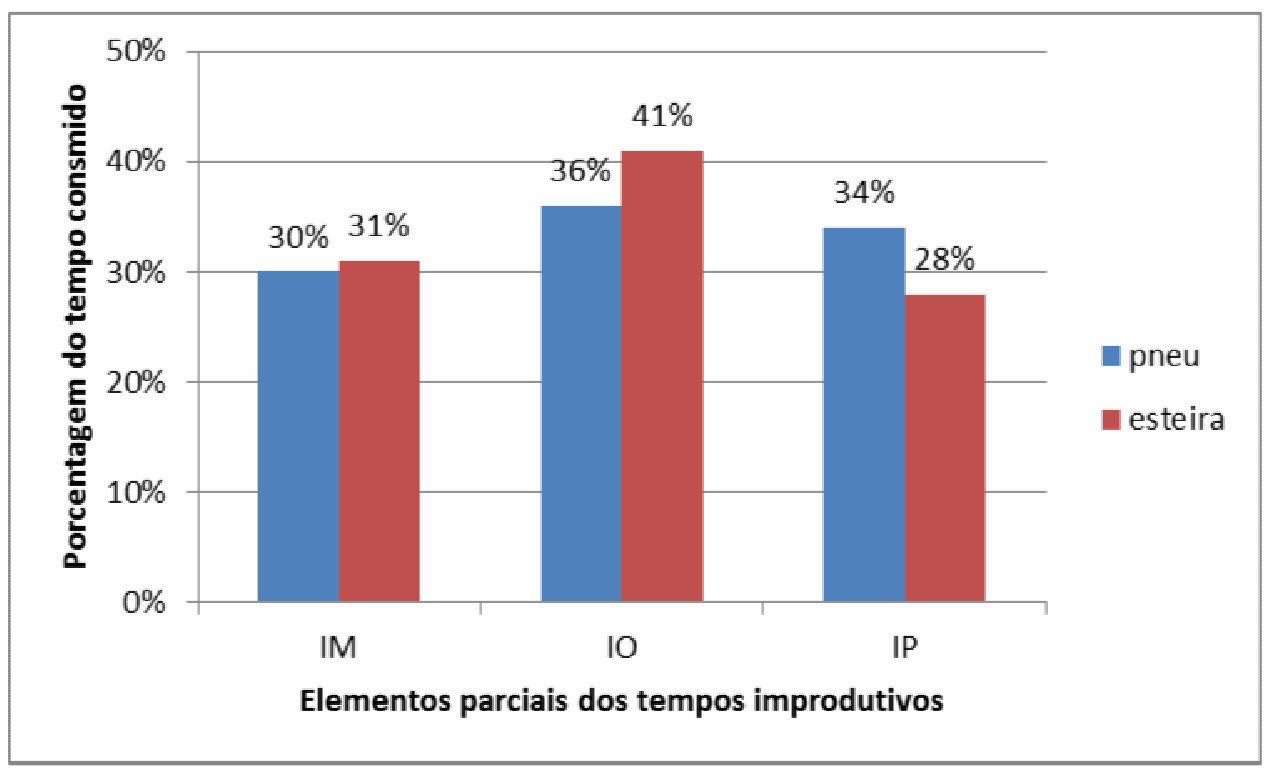

FIGURA 3 Distribuição percentual dos tempos improdutivos do corte florestal com o harvester de pneus e esteiras

$\mathrm{Na}$ Tabela 2 é apresentado os tempos de interrupções com representatividade igual ou maior a $10 \%$ em sua categoria, de modo a identificar os 
gargalos existentes na operação de corte. Tal fato foi observado por OLIVEIRA JÚNIOR et al. (2009), que dizem que o elevado custo das máquinas florestais demanda sua utilização durante o maior tempo possível com elevada produtividade. Como pode ser observado, a fase de maior representativa nas "interrupções operacionais" em ambas as máquinas foi o deslocamento interno, ocasionado quando as máquinas transitavam dentro do próprio talhão.

TABELA 2 Causas das interrupções no corte com o harvester de pneus e esteiras

\begin{tabular}{|c|c|c|c|c|c|c|}
\hline $\begin{array}{l}\text { Tipo de } \\
\text { rodados do } \\
\text { harvester }\end{array}$ & $\begin{array}{l}\text { Interrupção } \\
\text { Operacional }\end{array}$ & (\%) & $\begin{array}{l}\text { Interrupção } \\
\text { Mecânica }\end{array}$ & (\%) & $\begin{array}{c}\text { Interrupção } \\
\text { Pessoal }\end{array}$ & (\%) \\
\hline \multirow{5}{*}{ Pneus } & $\begin{array}{l}\text { Deslocamento } \\
\text { interno }\end{array}$ & 21 & Troca de corrente & 30 & Almoço & 84 \\
\hline & $\begin{array}{l}\text { Organização de } \\
\text { galhos }\end{array}$ & 19 & $\begin{array}{l}\text { Completar óleo } \\
\text { do cabeçote }\end{array}$ & 12 & Café & 11 \\
\hline & Checklist & 17 & Outros & 58 & Outros & 5 \\
\hline & $\begin{array}{c}\text { Organização de } \\
\text { toras }\end{array}$ & 11 & & & & \\
\hline & Outros & 32 & & & & \\
\hline \multirow{5}{*}{ Esteiras } & $\begin{array}{l}\text { Deslocamento } \\
\text { interno }\end{array}$ & 30 & $\begin{array}{l}\text { Troca da roda } \\
\text { medidora }\end{array}$ & 38 & Almoço & 72 \\
\hline & Checklist & 17 & Abastecimento & 15 & Outros & 28 \\
\hline & Outros & 53 & Troca da corrente & 14 & & \\
\hline & & & $\begin{array}{c}\text { Lubrificação da } \\
\text { corrente }\end{array}$ & 10 & & \\
\hline & & & Outros & 23 & & \\
\hline
\end{tabular}

O deslocamento interno afetou com maior intensidade a máquina com rodados de esteiras, com $30 \%$ do tempo demandado, enquanto na de pneus $21 \%$ do tempo demandado. Tal fato pode ser explicado pela maior velocidade de locomoção da máquina com rodados de pneus comparados à máquina de esteiras, que mesmo possuindo menor força de tração, possui maior mobilidade e velocidade de deslocamento.

Entretanto, houve diversas pequenas fases que também influenciaram com maior intensidade as ações operacionais do harvester com rodados de esteiras, que apresentaram tempos inferiores a $10 \%$ das interrupções operacionais, mas que em sua totalidade somaram $53 \%$. Dentre estas fases, cita-se as trocas de turno, problemas com galhos, calibração do computador da máquina, observação da área, instruções do supervisor e troca de informações via rádio.

Nas "interrupções mecânicas", destaca-se a troca da corrente do sabre, demandando $30 \%$ das interrupções no harvester de pneus e $14 \%$ no de esteiras, que trata-se de uma atividade rotineira da operação. Outras fases comprometeram a disponibilidade mecânica, sobressaindo a troca da roda medidora com $38 \%$ do tempo total, cujo defeito impedia o computador da máquina realizar a medição correta do sortimento. Destaca-se ainda o abastecimento com 15\% e a lubrificação da corrente com $15 \%$ dos tempos demandados com interrupções mecânicas.

Nas "interrupções pessoais", o almoço demandou $84 \%$ do tempo de interrupções pessoais para o trabalho com harvester de pneus e $72 \%$ no de esteiras. 
Ressalta-se a maior intensidade de pausas e necessidades fisiológicas, elevando a fase denominada "outros" a demandar $28 \%$ das interrupções nesta categoria para o harvester de esteiras.

Portanto, os resultados mostraram a necessidade de modificações na operação de corte para ambas as máquinas, sendo recomendadas ações visando a diminuição das "interrupções" (INT), e principalmente nas interrupções operacionais, pois, de acordo com LINHARES et al. (2012), estas possuem importante influência no tempo total de trabalho das máquinas.

A disponibilidade mecânica, eficiência operacional e produtividade de ambos os harvesters são apresentados na Tabela 3. Como pode ser visto, a maior diferença absoluta entre os valores ocorreu na eficiência operacional, resultante da influência das "interrupções operacionais" no tempo total trabalhado.

TABELA 3 Disponibilidade mecânica, eficiência operacional e produtividade média do harvester de pneus e esteiras

\begin{tabular}{ccc}
\hline \multirow{2}{*}{ Características } & \multicolumn{2}{c}{ Tipos de Rodados } \\
\cline { 2 - 3 } & Pneus & Esteiras \\
\hline Máquina Base & Valmet 911.3 & Komatsu PC 200 \\
Cabeçote & Valmet 360 & Valmet 370 \\
Disponibilidade mecânica $(\%)$ & 89,0 & 87,0 \\
Eficiência operacional $(\%)$ & 64,0 & 58,0 \\
Produtividade $\left(\mathrm{m}^{3} \mathrm{cc} / \mathrm{he}\right)$ & 36,9 & 35,0 \\
\hline
\end{tabular}

A máquina com rodados de pneus apresentou uma disponibilidade mecânica de $89 \%$ e eficiência operacional de $64 \%$, perfazendo uma produtividade média de $36,9 \mathrm{~m}^{3} \mathrm{cc} / \mathrm{he}$. Tais valores foram superiores aos obtidos na máquina com rodados de esteiras, com $87 \%$ de disponibilidade mecânica, $58 \%$ de eficiência operacional e produtividade de $35,0 \mathrm{~m}^{3} \mathrm{cc} / \mathrm{he}$.

É importante ressaltar que o harvester de esteiras apresentou valores menores ao de espeiras, mesmo trabalhando com sortimento que favorecia $(4,1 \mathrm{~m}$ no sortimento 3, em comparação aos $2,65 \mathrm{~m}$ no mesmo sortimento na máquina de pneus). Entretanto, os valores observados em ambas as máquinas podem ser considerados baixos, quando comparados aos encontrados por outros autores, como MAC DONAGH et al. (2013), LINHARES et al. (2012) e LOPES et al. (2007). Além disso, MACHADO (1989) recomenda que a eficiência operacional de máquinas de colheita florestal não deve ficar abaixo de $70 \%$.

JOHANSSON (1995), citado por SEIXAS \& BATISTA (2014), concluiu que três modelos de harvesters montados em escavadoras adaptadas apresentaram produtividades semelhantes às máquinas florestais especializadas (pneus), porém com custos operacionais menores, em virtude do menor valor de aquisição. Já SPENCER (1992) ressalta que a máquina adaptada apresenta restrições para trabalho em corte raso em terrenos inclinados, não devendo ultrapassar $38 \%$ de inclinação "morro acima" e 20\% "morro abaixo", além de volume por árvore máximo de $0,5 \mathrm{~m}^{3}$.

LOPES et al. (2007) estudaram o corte de madeira de pinus em diferentes condições operacionais com um harvester de esteiras, onde observaram produtividades médias entre $31,6 \mathrm{~m}^{3} / \mathrm{h}$ e $34,4 \mathrm{~m}^{3} / \mathrm{h}$, com eficiências operacionais médias entre $76,5 \%$ e $85,0 \%$. Os autores afirmaram que o elemento que consumiu a maior parte do tempo do ciclo operacional foi o processamento da madeira, com 
aproximadamente $55 \%$ do tempo total em todas as condições operacionais avaliadas.

Os custos operacionais e de produção dos harvesters de pneus e de esteiras estudados são mostrados na Tabela 4. De modo geral, os custos do harvester de esteiras foram menores em relação aos de pneus, que foram afetados principalmente pelos custos fixos, que foram menores devido ao menor valor de aquisição da máquina.

TABELA 4 Custo operacional e de produção do corte com o harvester de pneus e esteiras

\begin{tabular}{lccc}
\hline \multicolumn{1}{c}{ Características } & \multicolumn{2}{c}{ Tipos de Rodados } \\
\cline { 3 - 4 } & \multirow{2}{*}{ Máquina Base } & Pneus & Esteiras \\
Cabeçote & & Valmet 911.3 & Komatsu PC 200 \\
Rodados & Pneus & Valmet 370 \\
\hline Custos Fixos & Depreciação & 77,59 & Esteiras \\
(R\$/he) & Juros e seguros & 6,99 & 37,54 \\
& Combustível & 43,61 & 3,67 \\
\hline & Lubrificantes e óleos & 8,72 & 52,28 \\
Custos Variáveis & Material rodante & 8,45 & 5,23 \\
(R $\$ /$ he) & Manutenção e reparos & 27,55 & 3,25 \\
& Sabre e corrente & 8,32 & 21,35 \\
& Custo de pessoal & 39,55 & 8,32 \\
Custo de Administração $(\mathrm{R} \$ /$ he) & 9,39 & 62,35 \\
\hline Custo Operacional Total $(\mathrm{R} \$ /$ he) & 230,17 & 4,94 \\
\hline Custo de Produção $\left(\mathrm{R} \$ / \mathrm{m}^{3}\right)$ & 6,23 & 198,92 \\
\hline
\end{tabular}

No caso do harvester de pneus, os custos fixos foram afetados principalmente pela depreciação da máquina ( $\mathrm{R} \$ 77,59 / \mathrm{he})$, estando diretamente relacionado ao seu elevado custo de aquisição e à quantidade de horas trabalhadas, que neste caso, a máquina trabalhava apenas um turno de 10 horas, enquanto o harvester de esteiras trabalhava três turnos de oito horas.

Em relação aos custos variáveis do harvester de pneus, destaca-se o custo de combustível com $R \$ 43,61 /$ he, seguido pelo custo de pessoal com $R \$ 39,55$ e de manutenção e reparos com $R \$ 27,55 /$ he. No harvester de esteiras, os custos de combustíveis e de pessoal foram superiores com $R \$ 52,28 /$ he e $R \$ 62,35 /$ he, respectivamente, ocasionado principalmente pelo maior tempo de operação diária da máquina em relação à máquina de pneus.

Sendo assim, com uma produtividade média de $36,9 \mathrm{~m}^{3} / \mathrm{he}$ e custo operacional total de $\mathrm{R} \$ 230,17 /$ he, o custo de produção do harvester de pneus foi de $\mathrm{R} \$ 6,23 / \mathrm{m}^{3}$, estando próximo ao valor encontrado por SEIXAS \& BATISTA (2014). Enquanto isso, o harvester de esteiras apresentou uma produtividade média de 35,0 $\mathrm{m}^{3} /$ he e custo operacional total de $R \$ 198,92 /$ he, perfazendo um custo de produção de $R \$ 5,68 / \mathrm{m}^{3}$, semelhante ao obtido por SILVA et al. (2010) com $R \$ 5,99 / \mathrm{m}^{3}$.

Desta forma, cabe uma readequação do trabalho em ambas as máquinas, de forma que ao aumento da produtividade, eficiência operacional e disponibilidade 
mecânica, em níveis competitivos e rentáveis para a operação de corte, com destaque na melhoria da gestão de produção e manutenção.

\section{CONCLUSÕES}

Com base na análise e discussão dos resultados, conclui-se que:

- O "processamento" foi o elemento que consumiu o maior tempo do ciclo operacional em ambos os modelos de harvester, afetado pela necessidade de produção de elevada quantidade de sortimentos de toras.

- $\quad$ O tempo de trabalho do harvester de esteiras foi afetado pelo deslocamento no interior do talhão devido sua menor velocidade em relação à máquina de pneus.

- O harvester de esteiras apresentou menor eficiência operacional e produtividade, mesmo trabalhando com sortimentos que favorecia o seu melhor desempenho.

- Os custos do harvester de esteiras foram menores em relação ao de pneus, sendo afetado pelo menor valor de aquisição da máquina, e podendo ser indicado como o modelo mais adequado para uso no corte da madeira nas condições estudadas.

\section{AGRADECIMENTOS}

À Fundação Araucária pela concessão de bolsa de iniciação científica ao aluno de graduação e à empresa florestal pela disponibilização das máquinas e da área de estudo.

\section{REFERÊNCIAS}

BARNES, R. M. Estudo de movimentos e de tempos: projeto e medida do trabalho. 6 ed. São Paulo: Edgar Blücher, 1977.

LEONELLO, E. C.; GONÇALVES, S. P.; FENNER, P. T. Efeito do tempo de experiência de operadores de harvester no rendimento operacional. Árvore, Viçosa, MG, v.36, n.6, p.1129-1133, 2012.

LINHARES, M.; SETTE JÚNIOR, C. R.; CAMPOS, F.; YAMAJI, F. M. Eficiência e desempenho operacional de máquinas harvester e forwarder na colheita florestal. Pesquisa Agropecuária Tropical, Goiânia, GO, v. 42, n. 2, p. 212-219, abr./jun. 2012.

LOPES, E. S.; CRUZIANINI, E.; DIAS, A. N.; FIEDLER, N. C. Avaliação técnica e econômica do corte de madeira de pinus com cabeçote harvester em diferentes condições operacionais. Floresta, Curitiba, PR, v. 37, n. 3, set./dez. 2007.

LOPES, E.S. Aplicação do programa SNAP III (Scheduling and Network Analysis Program) no planejamento da colheita e do transporte florestal. Viçosa, MG: UFV, 2001. 150 f. (Tese de Doutorado em Ciência Florestal), Universidade Federal de Viçosa, Viçosa.

MAC DONAGH, P.; HILDT, E.; FRIEDL, R. A.; ZADERENKO, C.; ALEGRANZA, D. A. Influencia de la intensidad de raleos en la performance de un harvester de ruedas 
en el noreste argentino. Floresta, Curitiba, PR, v. 43, n. 4, p. 653 - 662, out. / dez. 2013.

MACHADO, C. C. Exploração florestal. Viçosa: Imprensa Universitária, 1989, 34 p.

MACHADO, C.C. Colheita florestal. 2a ed. Viçosa, MG, Ed. UFV, 2008.

OLIVEIRA JÚNIOR, E. D. O.; SEIXAS, F.; BATISTA, J. L. F. Produtividade de fellerbuncher em povoamento de eucalipto em relevo acidentado. Floresta, Curitiba, PR, v. 39, n. 4, p. 905-912, out./dez. 2009.

OLIVEIRA, A. J. Prefácio. In: Colheita florestal. 3. ed. Viçosa: Editora UFV, p. 74105.2014.

PULKKI, R. E. Glossary of forest harvesting terminology. 2006. Disponível em: <flash.lakeheadu.ca/ repulkki/REP_terminology.pdf> Acesso em: 15 out. 2009.

SANT'ANNA, C. M. Corte. In: Colheita florestal. 3. ed. Viçosa: Editora UFV, p. 74105.2014.

SEIXAS, F.; BATISTA, J. L. F. Comparação técnica e econômica entre harvesters de pneus e com máquina base de esteiras. Ciência Florestal, Santa Maria, v. 24, n. 1, p. 185-191, jan/mar., 2014.

SILVA, E. N.; MACHADO, C. C.; MINETTE, L. J.; SOUZA, A. P.; FERNANDES, H. C.; SILVA, M. L.; JACOVINE, L. A. Avaliação técnica e econômica do corte mecanizado de Pinus sp. com harvester. Árvore, Viçosa-MG, v.34, n.4, p.745-753, 2010. 